\title{
Indikasi Sesar Naik di Plampang, Pulau Sumbawa Berdasarkan Analisis Gempa Bumi 13 Juni 2020
}

\section{An Indication of a Reverse Fault in Plampang, Sumbawa Island Based on The June 13, 2020 Earthquake Analysis}

\author{
Priyobudi, Mohamad Ramdhan* \\ Badan Meteorologi, Klimatologi dan Geofisika \\ Jl. Angkasa 1 No. 2 Kemayoran, Jakarta 10720, Indonesia \\ *E-mail: mohamad.ramdhan@bmkg.go.id
}

Naskah diterima: 11 Maret 2021, direvisi: 29 Oktober 2021, disetujui: 5 November 2021

DOI: 10.17146/eksplorium.2021.42.2.6273

\begin{abstract}
ABSTRAK
Keberadaan sesar aktif dengan pola sesar naik di daerah Plampang berhasil diungkap dari sebaran hiposenter terelokasi, hasil inversi momen tensor, dan pemodelan perubahan tegangan Coulomb. Studi ini juga berhasil mengungkap sumber gempa pada sesar aktif tersebut dengan kedalaman relatif dangkal yang bisa menjadi ancaman di Pulau Sumbawa jika magnitudo maksimumnya rilis di masa yang akan datang. Hasil relokasi hiposenter menunjukkan sebaran episenter berarah barat daya-timur laut. Hal ini didukung juga oleh hasil inversi momen tensor yang menunjukkan bidang sesar berarah barat daya-timur laut $\left(\mathrm{N} 224^{\circ} \mathrm{E}\right)$ dengan dip cukup curam $\left(49^{\circ}\right)$. Penampang seismisitas vertikal pada arah dip menunjukkan adanya pola sesar naik yang semakin landai seiring bertambahnya kedalaman. Bidang sesar yang landai menunjukkan struktur decollement pada kedalaman 10-15 km dan berangsur menjadi curam sebagai struktur splay fault pada kedalaman 0-10 km. Hal tersebut konsisten dengan hasil inversi momen tensor yang menunjukkan mekanisme pergerakan sesar naik terjadi pada kedalaman $7 \mathrm{~km}$. Pemodelan perubahan tegangan Coulomb menunjukkan adanya penambahan stress di luar area bidang sesar sehingga memicu terjadinya aftershocks. Sebaran gempa susulan menunjukkan adanya bidang sesar hipotetik dengan panjang $19 \mathrm{~km}$ dan lebar $12 \mathrm{~km}$. Sesar sebesar ini berpotensi membangkitkan gempa dengan kekuatan $\mathrm{Mw}$ 6,4. Gempa Sumbawa 13 Juni 2020 dengan magnitudo M 5,3 disebabkan oleh sebagian kecil aktivitas dari bidang sesar tersebut.
\end{abstract}

Kata kunci: hiposenter, momen tensor, perubahan tegangan Coulomb, decollement, splay fault

\begin{abstract}
The existence of an active fault with a reverse fault mechanism in the Plampang area is successfully delineated from the distribution of the relocated hypocenter, the moment tensor inversion, and the Coulomb stress changes. This study also reveals the source of the earthquake in the active fault with a relatively shallow depth which can be a threat on Sumbawa Island if the maximum magnitude is released in the future. Seismicity from hypocenter relocation shows the distribution of the epicenter with a southwest-northeast direction. It is also supported by the moment tensor inversion result which shows the fault plane trending southwest-northeast $\left(N 224^{\circ} E\right)$ with a steep dip $\left(49^{\circ}\right)$. The vertical section of seismicity in the dip direction shows that the slope of the plane has a lower angle with increasing depth. The lower angle of a fault plane shows a decollement structure at a depth of 10-15 km and gradually becomes steep as a splay fault structure at a depth of 0-10 km. It is consistent with the result of moment tensor inversion which shows the mechanism of a reverse fault that occurred at a depth of $7 \mathrm{~km}$. The Coulomb stress changes show the stress increasing outside the fault plane area, which triggers aftershocks. The distribution of aftershocks shows a hypothetical fault plane of $19 \mathrm{~km}$ long and $12 \mathrm{~km}$ wide. A fault of this size has the potential to generate an earthquake with a magnitude maximum of Mw 6.4. The Sumbawa earthquake on June 13, 2020, having M 5.3 was caused by a small part of the activity from the fault.
\end{abstract}

Keywords: hypocenter, moment tensor, Coulomb stress change, decollement, splay fault 


\section{PENDAHULUAN}

Provinsi Nusa Tenggara Barat merupakan kawasan strategis karena merupakan salah satu tujuan pariwisata di Indonesia. Industri pariwisata dapat berjalan dengan baik jika kebutuhan energi listriknya terpenuhi. Kebutuhan listrik salah satunya bisa dipasok oleh Pembangkit Listrik Tenaga Nuklir (PLTN). Pemahaman kondisi tektonik yang baik pada suatu area rencana pembangunan tapak PLTN merupakan faktor penting yang harus dipertimbangkan untuk mitigasi bencana di wilayah tersebut sehingga kebocoran reaktor seperti yang terjadi di Fukushima, Jepang akibat gempa Sendai 2011 tidak terjadi di wilayah Indonesia.

Pulau Sumbawa merupakan wilayah yang memiliki tingkat aktivitas kegempaan tinggi [1]. Pada saat terjadi gempa bumi Lombok 19 Agustus 2018, Pulau Sumbawa mengalami guncangan antara IV hingga VI MMI [2]. Hal ini mengakibatkan kerusakan di beberapa wilayah tersebut. Aktivitas sesar aktif bukan merupakan satu-satunya ancaman bagi Pulau Sumbawa. Sejumlah penelitian telah dilakukan untuk mengungkap sumber gempa bumi di sekitar Busur Sunda-Banda termasuk di Pulau Sumbawa. Sesar naik belakang busur di bagian utara Pulau Sumbawa (Flores Back Arc Thrust) dan zona subduksi di selatan pulau tersebut merupakan sumber gempa besar yang mengancam pulau ini [3]. Penelitian lain menyebutkan adanya sesar mendatar berarah utara-selatan tepat di selatan Pulau Sumbawa [3]. Penelitian geologi lapangan untuk mengungkap keberadaan sesar aktif di daerah Plampang, Pulau Ngali, dan Pulau Rakit tidak menunjukkan adanya indikasi pensesaran di permukaan [4].

Pada tanggal 13 Juni 2020, gempa bumi dengan kekuatan menengah (M 5,3) terjadi di sekitar Plampang, Sumbawa, Nusa Tenggara Barat (NTB). Gempa tersebut diikuti oleh sejumlah gempa susulan yang cukup signifikan. Guncangan gempa bumi dirasakan di Pulau Sumbawa, Pulau Lombok, dan Pulau Bali. Intensitas maksimum sebesar IV MMI dirasakan di Sumbawa dan intensitas minimum dirasakan II MMI di daerah Karangasem, Bali [5]. Gempa ini sangat menarik untuk diteliti lebih lanjut karena dapat menjadi bukti baru adanya sesar aktif dangkal. Penelitian ini dimaksudkan untuk mengungkap pola sesar aktif tersebut berdasarkan data hiposenter gempa yang terelokasi, analisis mekanisme fokal, dan perubahan tegangan Coulomb. Pola sesar yang diungkap meliputi arah strike, dip, dan perkiraan dimensi panjang dan lebarnya.

Hasil penelitian ini akan menambah data baru sesar aktif di Indonesia, khususnya di Pulau Sumbawa. Pengetahuan tentang kondisi seismotektonik di suatu wilayah sangat berguna dalam upaya mitigasi bencana gempa bumi. Hasil penelitian ini juga sangat penting di dalam perencanaan pembangunan sarana vital seperti bandara, kawasan industri, reaktor nuklir, dan sebagainya.

\section{DATA DAN METODE}

Katalog gempa bumi yang digunakan pada studi ini berasal dari katalog Balai Besar Meteorologi, Klimatologi, dan Geofisika (BBMKG) wilayah III, Bali. Penggunaan data katalog BBMKG III pada studi ini sangat penting karena berhasil mendeteksi aftershocks yang signifikan akibat gempa $\mathrm{M}$ 5,3 sehingga aftershock tersebut bisa digunakan untuk mengungkap struktur sesar yang mengakibatkan gempa tersebut. Data yang digunakan untuk studi ini adalah data dari tanggal 13 Juni-3 Juli 2020 (20 hari) pada rentang koordinat $116^{0}-120^{\circ} \mathrm{BT}$ dan $8^{0}-10^{0} \mathrm{LS}$. Gempa-gempa yang tidak berkaitan dengan gempa susulan diabaikan atau tidak digunakan. Gempa-gempa tersebut berkaitan 
dengan gempa dalam yang berkaitan dengan aktivitas seismik di zona subduksi. Adapun metode relokasi hiposenter yang digunakan untuk studi ini menggunakan metode teleseismic double-differerence dengan model kecepatan 3-D [6-8]. Parameter katalog yang digunakan berupa parameter hiposenter $\left(\mathrm{x}_{0}, \mathrm{y}_{0}, \mathrm{Z}_{0}, \mathrm{t}_{0}\right)$ dan waktu tempuh gelombang $\mathrm{P}$ dan $S$ yang dicatat oleh stasiun-stasiun seismik yang merekam gempa. Kriteria minimum data yang digunakan pada studi ini paling tidak dicatat oleh enam fase gelombang seismik, baik gelombang $\mathrm{P}$ dan $\mathrm{S}$ atau $\mathrm{P}$ saja. Kriteria ini juga digunakan untuk mendeliniasi sesar aktif Palu-Koro pada segmen Palu [9].

Inversi momen tensor dilakukan untuk mendapatkan data mekanisme fokal yang berfungsi untuk mengetahui mekanisme sumber gempa M 5,3. Metode inversi yang digunakan untuk menentukan mekanisme sumber gempa adalah metode stable inversion for the complete moment tensor algorithm yang paket programnya terdapat pada aplikasi SeiscomP yang digunakan oleh Badan Meteorologi, Klimatologi, dan Geofisika (BMKG) untuk pengolahan parameter gempa bumi yang terdiri dari parameter hiposenter, magnitudo, dan mekanisme fokal [10].

Perkiraan perubahan tegangan di sekitar zona sesar pada studi ini dilakukan juga untuk memahami hubungan antara gempa utama dan sebaran gempa-gempa susulannya. Perkiraan tersebut dianalisis menggunakan pemodelan Coulomb Stress [11].

\section{HASIL DAN PEMBAHASAN}

Observasi gempa susulan akibat gempa $\mathrm{M}$ 5,3 selama 20 hari menghasilkan 220 gempa susulan. Total jumlah gempa yang direlokasi hiposenternya pada studi ini sejumlah 221, termasuk gempa utama M 5,3. Sebanyak 135 gempa berhasil direlokasi hiposenternya. Sejumlah gempa tidak dapat direlokasi karena tidak memenuhi persyaratan untuk proses inversi sehingga tidak ditemukan solusi yang konvergen.

Sebaran gempa susulan sebelum direlokasi menunjukkan kluster episenter berarah barat laut-tenggara. Sementara itu, sebaran gempa susulan yang terelokasi menunjukkan kluster yang lebih sempit dengan arah sebaran barat daya-timur laut. Beberapa gempa susulan (sebelum direlokasi) yang berada di laut selatan Sumbawa telah bergeser ke dalam area persegi panjang merah. Episenter gempa utama yang sebelumnya berada di laut setelah direlokasi episenternya bergeser ke daratan Pulau Sumbawa (Gambar 1b). Hal ini sesuai dengan kemiringan bidang sesar yang mengarah ke barat laut di bawah daratan Pulau Sumbawa. Area persegi panjang merah adalah bidang sesar hipotetik berdasarkan sebaran gempa susulan terelokasi (Gambar 1b).

Analisis melalui penampang melintang sebaran hiposenter dilakukan untuk mengetahui penyebab struktur sesar gempa $\mathrm{M}$ 5,3. Hasil relokasi menunjukkan perubahan yang sangat signifikan dalam hal kedalaman hiposenter. Sejumlah hiposenter yang terletak di kedalaman $10 \mathrm{~km}$ (fix depth) telah terelokasi ke kedalaman yang semestinya (Gambar 2b dan 2d). Sebaran hiposenter sebelum dilakukan relokasi tidak menunjukkan adanya seismisitas pada kedalaman 0-10 km (Gambar 2a dan 2c). Setelah direlokasi, beberapa hiposenter bergeser ke kedalaman 0-10 km dan sebarannya membentuk pola tertentu (Gambar 2b dan 2d). 
a)

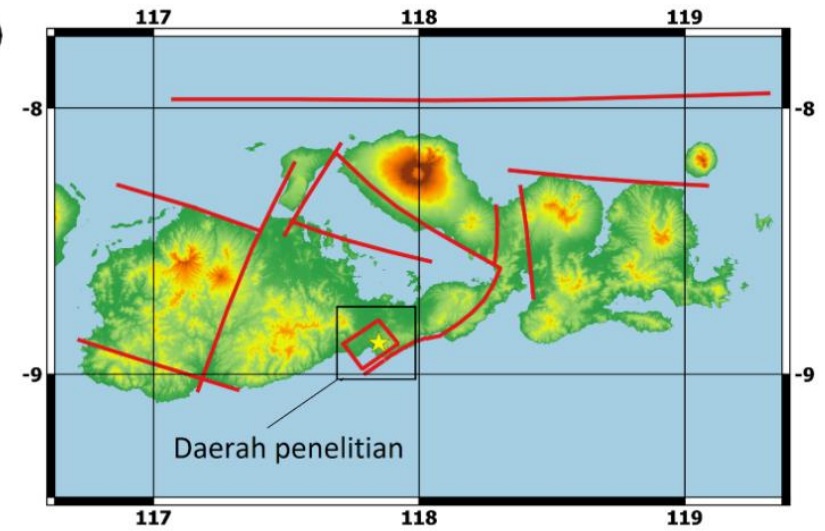

b)

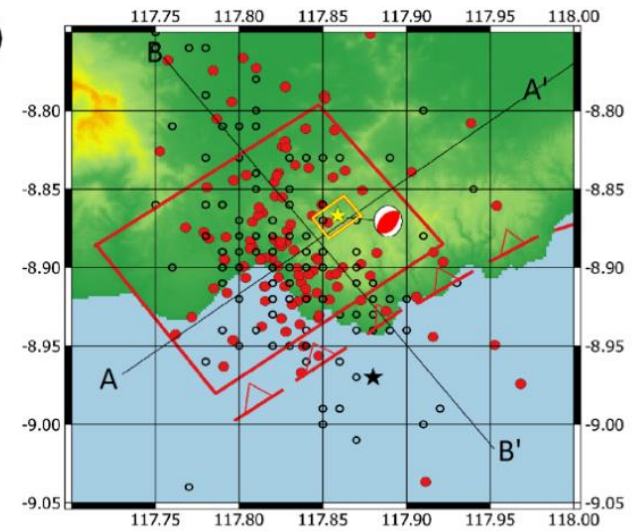

Gambar 1. Pola struktur geologi regional di Pulau Sumbawa dan sekitarnya berdasarkan hasil studi terdahulu [12] (a). Area penelitian ditunjukkan dengan area persegi panjang hitam. Sebaran episenter gempa susulan sebelum relokasi (lingkaran hitam) dan setelah direlokasi (lingkaran merah) (b). Persegi panjang kuning menunjukkan perkiraan bidang sesar pembangkit gempa M 5,3 dengan tanda bintang sebagai episenter gempa dan bola fokal menunjukkan mekanisme sesar naik. Persegi panjang merah menunjukkan bidang sesar hipotetik berdasarkan sebaran gempa susulan yang berpotensi membangkitkan gempa $\mathrm{Mw}$ 6,4. Garis putus-putus dengan segitiga berwarna merah adalah garis sesar [12]. Gempa utama setelah relokasi ditunjukkan oleh bintang kuning dan sebelum relokasi ditunjukkan oleh bintang hitam.

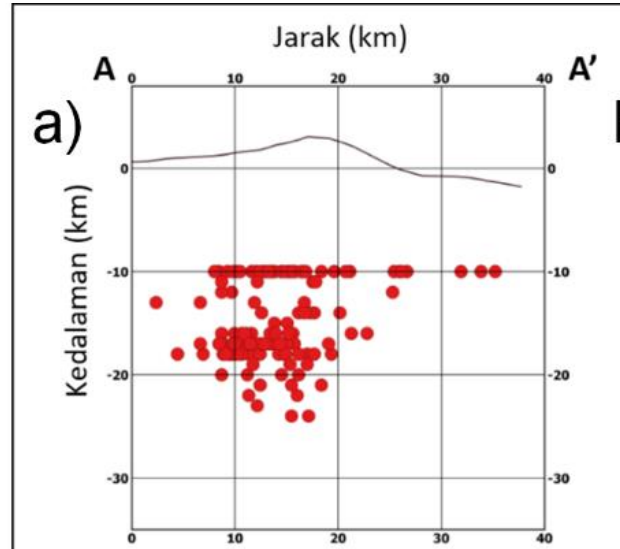

a)

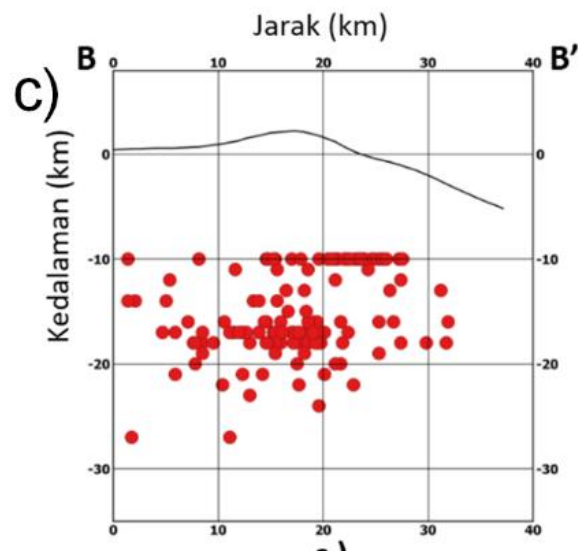

c)

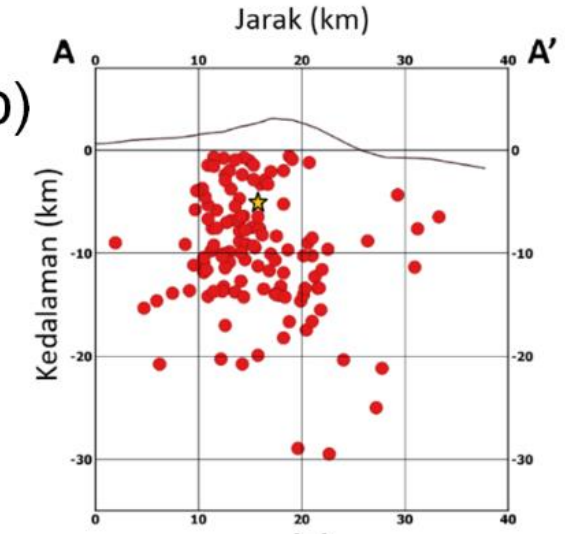

b)

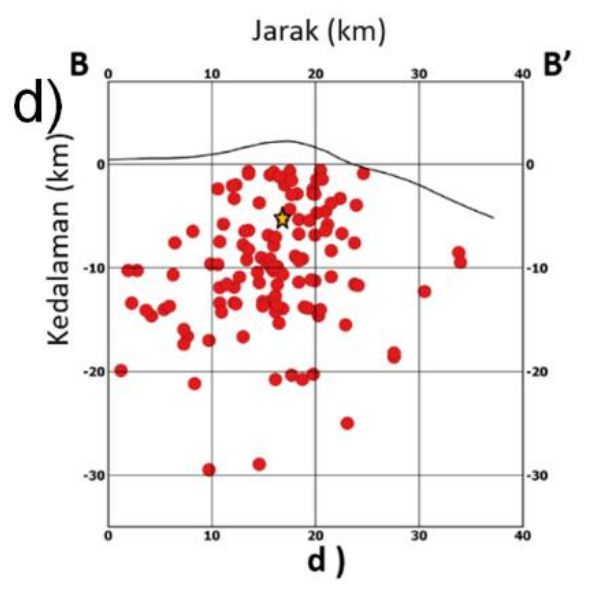

Gambar 2. Penampang vertikal sebaran hiposenter sebelum (a) dan sesudah (b) direlokasi pada arah strike. Penampang vertikal sebaran hiposenter sebelum (c) dan sesudah (d) direlokasi pada arah dip. Penampang topografi berdasarkan data GEBCO dengan skala vertikal diperbesar 10 kali [13]. 
Hasil inversi momen tensor dari gempa utama disajikan dalam Tabel 1. Hasil inversi momen tensor menunjukkan variasi arah strike $\mathrm{N} 224^{\circ} \mathrm{E}$, dip $49^{\circ}$, rake $95^{\circ}$ (bidang nodal 1) dan strike $\mathrm{N} 36^{\circ} \mathrm{E}$, dip $40^{\circ}$, rake $83^{\circ}$ (bidang nodal 2). Parameter mekanisme fokal menunjukkan bahwa gempa ini memiliki mekanisme sesar naik. Kedalaman fokal sebesar $7 \mathrm{~km}$. Berdasarkan sebaran gempa susulannya, proses rupture gempa ini tampak merambat ke kedua arah, yaitu ke bagian up-dip dan downdip dari bidang sesar (Gambar 2d).

Perubahan tegangan Coulomb dihitung dengan menggunakan dimensi sesar 2,6 x 2,5 $\mathrm{km}^{2}$, dengan strike $\mathrm{N} 224^{\circ} \mathrm{E}$, dip $49^{0}$ dan rake $95^{\circ}$. Penambahan tegangan terjadi di ujung- ujung sesar pada arah strike (Gambar 3a). Perubahan tegangan Coulomb yang bernilai positif pada arah strike (barat daya-timur laut) menyebabkan perkembangan gempa susulan menyebar ke arah barat daya dan sedikit ke timur laut. Pada penampang vertikal tampak bahwa perubahan tegangan Coulomb positif terjadi di bagian up-dip dan down-dip bidang sesar (Gambar 3b). Hal ini menjelaskan mengapa gempa susulan banyak terjadi di bagian down-dip sesar. Sementara ke arah updip sesar, gempa susulan tidak begitu banyak terjadi karena kemungkinan ujung sesar telah habis dan adanya endapan Kuarter yang menutupi permukaan sesar.

Tabel 1. Parameter mekanisme fokal hasil inversi momen tensor.

\begin{tabular}{lc}
\hline Parameter & Nilai \\
\hline Magnitudo (Mw) & 4,9 \\
Momen Seismik & $2,8 \times 10^{16}$ \\
Waktu gempa (WIB) & $16: 15: 48$ \\
Bujur & $117,89^{0}$ \\
Lintang & $-9,13^{0}$ \\
Kedalaman (km) & 7,0 \\
Bidang Nodal 1 & Strike, dip, rake: $224^{0}, 49^{0}, 95^{\circ}$ \\
Bidang Nodal 2 & Strike, dip, rake: $36^{0}, 40^{\circ}, 83^{\circ}$ \\
\hline
\end{tabular}
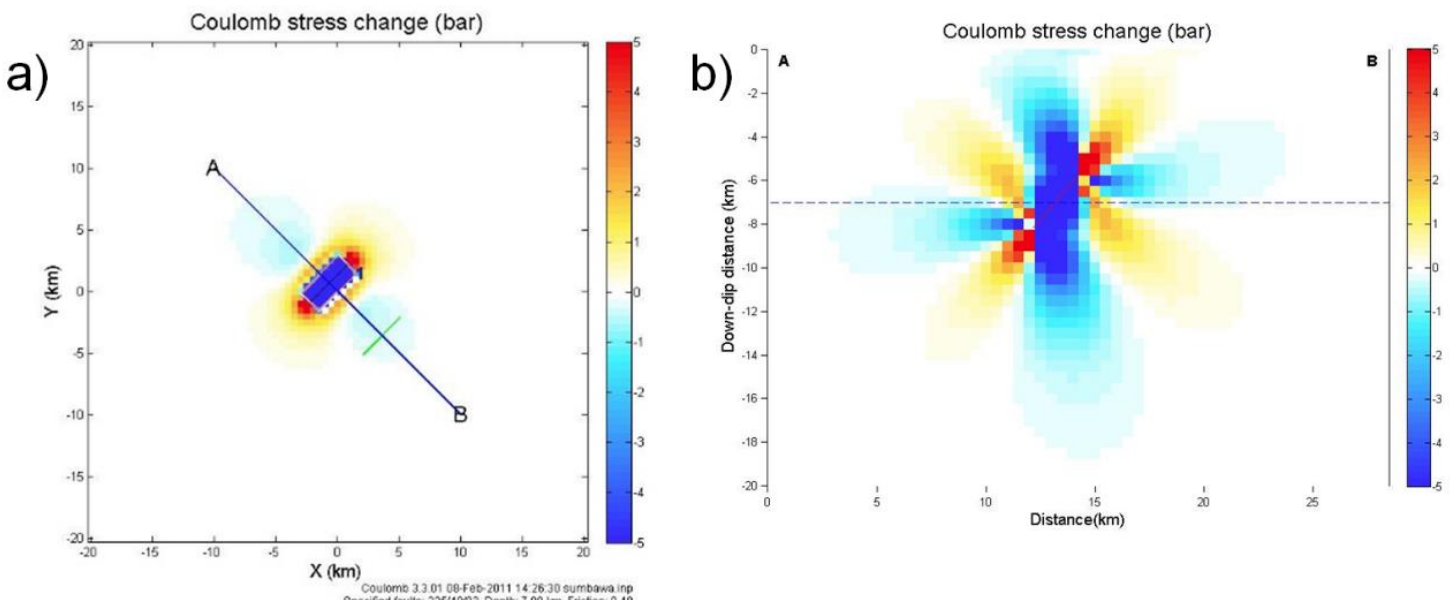

Gambar 3. Model Coulomb dari perubahan tegangan di sekitar bidang sesar pembangkit gempa Sumbawa M 5,3 tampak atas (a) dan tampak penempang searah dip bidang sesar (b). Penambahan tegangan terjadi di ujung-ujung searah strike sesar (a). Penambahan tegangan terjadi di bagian up-dip dan down-dip bidang sesar (b). 
Menurut teori Scalling Law [14], gempa dengan magnitudo moment Mw 4,9 memiliki ukuran panjang dan lebar bidang sesar sebesar 2,6 km x 2,5 km (persegi panjang kuning pada Gambar 1b). Jika bidang sesar ini diplot pada peta sebaran gempa susulan, tampak bahwa sebaran gempa susulan mendominasi daerah di luar bidang sesar. Gempa susulan berkembang ke arah strike sesar (barat daya-timur laut) dan ke arah down-dip sesar. Sebaran gempa susulan yang meluas di luar bidang sesar menunjukkan adanya bidang sesar hipotetik yang lebih besar berukuran $19 \mathrm{~km}$ x $12 \mathrm{~km}$ (persegi panjang merah pada Gambar 1b). Dimensi sesar sebesar ini setara dengan bidang sesar yang menghasilkan gempa Mw 6,4 [14]. Magnitudo maksimum pada sesar tersebut perlu diwaspadai dengan upaya mitigasi struktural seperti penguatan struktur bangunan, penguatan pada lereng-lereng rawan longsor, dan sebagainya.
Model skematik penampang vertikal struktur sesar pembangkit gempa Sumbawa dan gempa-gempa susulannya ditunjukkan dalam gambar 4. Interpretasi berdasarkan sebaran gempa susulan yang terelokasi pada penampang B-B' menunjukkan adanya bidang sesar landai (decollement) pada kedalaman 10-20 km. Sementara itu, mekanisme fokal gempa 13 Juni 2020 terjadi pada bidang sesar dengan dip yang cukup curam $\left(49^{\circ}\right)$. Berdasarkan data tersebut, selain bidang sesar yang landai terdapat juga bidang sesar curam sebagai splay fault. Interpretasi penampang struktur sesar juga didukung oleh data topografi. Topografi perbukitan yang berada tepat di ujung atas bidang sesar merupakan manifestasi dari adanya sesar naik ini (Gambar 4). Hangingwall sesar tersebut berada di bagian daratan sementara bagian footwall berada di lautan.

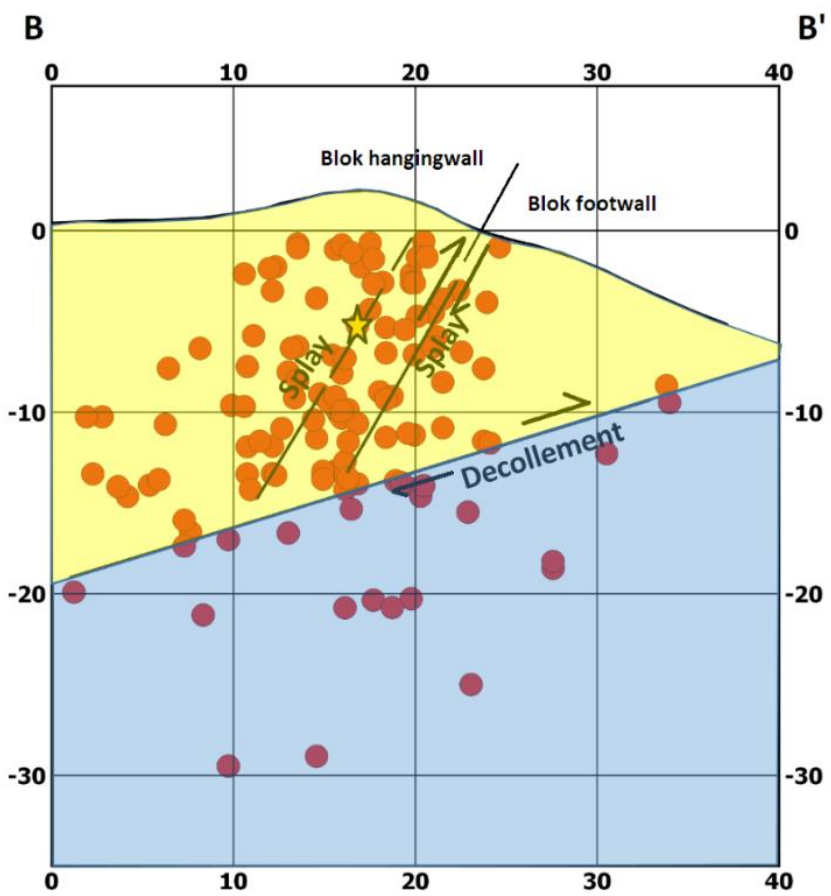

Gambar 4. Model skematik struktur sesar naik (garis hitam) yang diinterpretasi dari sebaran hiposenter pada arah dip. Bintang kuning menunjukkan lokasi gempa utama. Penampang topografi berdasarkan data GEBCO dengan skala vertikal diperbesar 5 kali [13]. 
Penelitian terdahulu menunjukkan adanya sesar naik berarah barat-timur melewati Teluk Saleh yang ditafsirkan dari kelurusan data anomali gravitasi [15]. Orientasi sesar yang berarah barat-timur serta lokasi indikasi sesar yang terlalu ke utara tidak sesuai dengan sebaran hiposenter gempa Sumbawa 13 Juni 2020. Pusat Studi Gempa Nasional atau PuSGeN tidak melaporkan adanya sesar aktif di daerah Teluk Saleh. Penelitian lain menunjukkan adanya sesar aktif yang berada di selatan Pulau Sumbawa atau tepatnya di Teluk Panas. Sesar ini berupa sesar mendatar dengan arah utara-selatan [3]. Peta struktur geologi Pulau Sumbawa terdahulu menunjukkan adanya beberapa sesar di daratan Pulau Sumbawa [12]. Salah satu sesar tersebut bersesuaian dengan proyeksi permukaan bidang sesar hasil studi ini (Gambar 1a). Menurut peta tersebut, sesar naik ini berarah barat daya-timur laut dan bagian timurnya dipotong oleh sesar lain yang berarah barat laut-tenggara (Gambar 1a).

\section{KESIMPULAN}

Hasil relokasi data hiposenter, inversi momen tensor, dan pemodelan perubahan tegangan Coulomb telah berhasil mengungkap adanya sesar aktif di daerah Plampang, Pulau Sumbawa. Pola sesar naik penyebab gempa tersebut dapat diinterpretasikan dari dua data pertama. Penelitian ini mengungkap adanya sesar aktif yang relatif dangkal yang menjadi ancaman bagi Pulau Sumbawa jika gempa dengan magnitudo maksimum pada kedalaman dangkal rilis di masa mendatang. Hasil relokasi hiposenter gempa menunjukkan sebaran episenter berarah barat daya-timur laut. Hal ini didukung juga oleh hasil inversi momen tensor yang menunjukkan bidang sesar berarah barat daya-timur laut yang memiliki mekanisme pergerakan naik dengan dip yang relatif curam dengan kedalaman dangkal (7 $\mathrm{km})$. Sebaran hiposenter pada arah strike dan arah down-dip sesar bersesuaian dengan perubahan tegangan Coulomb yang bernilai positif di daerah tersebut. Hal ini menunjukkan gempa utama terjadi pada struktur splay fault dan gempa susulan merambat dari struktur splay fault ke struktur decollement. Gempa Sumbawa 13 Juni 2020 diakibatkan oleh aktivitas sesar yang belum terpetakan. Berdasarkan sebaran gempa bumi susulan, terdapat bidang sesar hipotetik yang berpotensi membangkitkan gempa $\mathrm{Mw}$ 6,4 sehingga diperlukan penelitian lebih lanjut untuk memahami karakteristik sesar ini. Selain itu, upaya mitigasi struktural dan kultural sangat penting untuk meminimalkan korban jiwa, luka-luka, dan kerusakan infrastruktur.

\section{UCAPAN TERIMA KASIH}

Ucapan terima kasih yang tak terkira kami sampaikan kepada Balai Besar Meteorologi, Klimatologi, dan Geofisika (BBMKG) wilayah III yang telah memberikan data katalog gempa bumi. Penelitian ini didukung oleh Komite Kajian Gempa Bumi dan Tsunami BMKG 2021.

\section{DAFTAR PUSTAKA}

[1] R. McCaffrey, "Active Tectonics of the Eastern Sunda and Banda Arcs," Journal of Geophysical Research Atmospheres, vol. 931, no. B12, pp. $15163-15182$ 1988 ,

doi: 10.1029/JB093iB12p15163.

[2] BMKG, "Pulau Lombok Kembali Diguncang Gempabumi $\mathrm{M}=7.0$, Tidak Berpotensi Tsunami", bmkg, 20 Agustus 2018, [Online]. Tersedia: https://www.bmkg.go.id/press-release/?p=pulaulombok-kembali-diguncang-gempabumi-m7-0tidak-berpotensi-tsunami\&tag=pressrelease\&lang=ID [Diakses: 24 Februari 2021].

[3] Pusat Studi Gempa Nasional (PuSGeN), "Peta Sumber dan Bahaya Gempa Indonesia Tahun 2017", Puslitbang Perumahan dan Permukiman, Balitbang Kementerian PUPR, 2017.

[4] S. Supartoyo, "Analisis Morfotektonik dan Pemetaan Geologi pada Identifikasi Sesar Permukaan di daerah Plampang, Pulau Ngali dan Pulau Rakit, Provinsi Nusa Tenggara Barat," 
Jurnal Pengembangan Energi Nuklir, vol. 21, no. 1, pp. 45-52, 2019, doi: 10.17146/jpen.2019.21.1.5461.

[5] M. Ramdhan, Priyobudi, A. Mursityanto, K. H. Palgunadi, dan Daryono, "Analysis of M 5.3 Sumbawa, Indonesia Earthquake 2020 and Its Aftershocks Based on Hypocenter Relocation from BMKG Seismic Stations," IOP Conf. Ser.: Earth Environ. Sci., vol. 873, no. 1, p. 012070, 2021, doi: 10.1088/1755-1315/873/1/012070.

[6] J. Pesicek, C. Thurber, H. Zhang, H. DeShon, E. Engdahl, dan S. Widiyantoro, "Teleseismic Double-Difference Relocation of Earthquakes Along the Sumatra-Andaman Subduction Zone Using a 3-D Model," Journal of Geophysical Research: Solid Earth, vol. 115, no. B10, 2010, doi: 10.1029/2010JB007443.

[7] S. Widiyantoro dan R. van der Hilst, "Mantle Structure Beneath Indonesia Inferred from HighResolution Tomographic Imaging," Geophysical Journal International, vol. 130, no. 1, pp. 167182, 1997, doi: 10.1111/j.1365246X.1997.tb00996.x.

[8] S. Widiyantoro dan R. van der Hilst, "Structure and Evolution of Lithospheric Slab Beneath the Sunda Arc, Indonesia," Science, vol. 271, no. 5255, pp. 1566-1570, 1996, doi: 10.1126/science.271.5255.1566.

[9] Priyobudi dan M. Ramdhan, "Rekonstruksi Model Bawah Permukaan Sesar Palu Berdasarkan Hasil Relokasi Hiposenter," Jurnal Lingkungan dan
Bencana Geologi, vol. 11, no. 1, pp. 1-9, 2020, doi: 10.34126/jlbg.v11i1.293.

[10] S. E. Minson dan D. S. Dreger, "Stable Inversions for Complete Moment Tensors," Geophys J Int, vol. 174, no. 2, pp. 585-592,. 2008, doi: 10.1111/j.1365-246X.2008.03797.x.

[11] G. C. P. King, R. S. Stein, dan J. Lin, "Static Stress Changes and the Triggering of Earthquakes," Bulletin of the Seismological Society of America, vol. 84, no. 3, pp. 935-953, 1994, doi: 10.1785/BSSA0840030935.

[12] A. Sudradjat dan B. Hermanto, "Peta Geologi Tinjau Sumbawa, Nusa Tenggara Barat, Puslitbang Geologi, Bandung, 1975.

[13] P. Weatherall, K. M. Marks, M. Jakobsson, T. Schmitt, S. Tani, J. E. Arndt, M. Rovere, D. Chayes, V. Ferrini, dan R. Wigley, "A New Digital Bathymetric Model of the World's Oceans," Earth and Space Science, vol. 2, no. 8, pp. 331-345, 2015 , doi: https://doi.org/10.1002/2015EA000107.

[14] D. L. Wells dan K. J. Coppersmith, "New Empirical Relationships among Magnitude, Rupture Length, Rupture Width, Rupture Area, and Surface Displacement," Bulletin of the Seismological Society of America, vol. 84, no. 4, pp. 974-1002, 1994, doi: 10.1785/BSSA0840040974.

[15] Pusat Survei Geologi, "Geodinamika dan Mekanisme Gempabumi Lombok", Prosiding Seminar Gempabumi Lombok di KESDM, 2018. 